OPEN ACCESS

Edited by:

Chiranjib Chakraborty, Galgotias University, India

Reviewed by: Andrea Huwiler University of Bern, Switzerland

Rink-Jan Lohman,

The University of Queensland, Australia

*Correspondence: Zhong Liu tliuzh@jnu.edu.cn Wen-Cai Ye

chywc@aliyun.com Man-Mei Li

limanmei@hotmail.com

† These authors have contributed equally to this work

Specialty section: This article was submitted to Experimental Pharmacology and Drug

Discovery,

a section of the journal

Frontiers in Pharmacology

Received: 11 February 2017 Accepted: 10 May 2017

Published: 26 May 2017

Citation:

Liu Q, Xiao $X-H, H u L-B$, Jie $H-Y$, Wang $Y$, Ye W-C, Li $M-M$ and Liu Z (2017) Anhuienoside C Ameliorates

Collagen-Induced Arthritis through Inhibition of MAPK and NF- $\kappa B$ Signaling Pathways.

Front. Pharmacol. 8:299. doi: 10.3389/fphar.2017.00299

\section{Anhuienoside C Ameliorates Collagen-Induced Arthritis through Inhibition of MAPK and NF-кB Signaling Pathways}

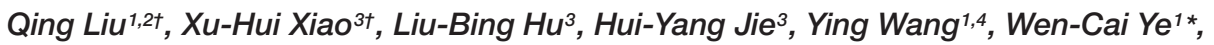
Man-Mei Li ${ }^{1 *}$ and Zhong Liü ${ }^{3 *}$

\footnotetext{
' Guangdong Province Key Laboratory of Pharmacodynamic Constituents of TCM and New Drugs Research, Jinan University, Guangzhou, China, ${ }^{2}$ College of Pharmacy, Xiangnan University, Chenzhou, China, ${ }^{3}$ Guangzhou Jinan Biomedicine Research and Development Center, Guangdong Provincial Key Laboratory of Bioengineering Medicine, College of Life Science and Technology, Jinan University, Guangzhou, China, ${ }^{4}$ College of Pharmacy, Jinan University, Guangzhou, China
}

Anemone flaccida Fr. Schmidt (Ranunculaceae) (Di Wu in Chinese) is used to treat punch injuries and rheumatoid arthritis (RA). Our previous report has shown that crude triterpenoid saponins from Anemone flaccida exhibited anti-arthritic effects on type II collagen-induced arthritis in rats. Furthermore, anhuienoside C (AC), a saponin compound isolated from $A$. flaccida, was observed to suppress the nitric oxide production in lipopolysaccharide (LPS)-treated macrophage RAW 264.7 cells. In this study, we examined the effects of AC on the prevention and treatment of collageninduced arthritis in a mouse model and evaluated the potential mechanisms involved. We observed that oral administration of AC significantly suppressed the paw swelling and arthritic score, decreased the body weight loss, and decreased the spleen index. Improvement in the disease severity was accompanied by the reduction of cluster of differentiation 68 (CD68)-positive cells in the ankle joint and inhibition of the proinflammatory cytokine tumor necrosis factor alpha (TNF- $\alpha$ ) in the synovium of the joint. Mechanistic studies indicated that AC exerted its anti-inflammatory activity by inhibiting the mRNA expression levels of inducible nitric oxide synthase, cyclooxygenase-2, TNF- $\alpha$, interleukin (IL)- $1 \beta$, and IL- 6 and by suppressing the production of inflammatory cytokines such as TNF- $\alpha, \mathrm{IL}-1 \beta$, and IL-6 in LPS-treated RAW 264.7 cells. AC also blocked the LPS-induced activation of the extracellular signal-regulated kinase, c-Jun $\mathrm{N}$-terminal kinase, and p38 mitogen-activated protein kinase pathways. Additionally, the LPS-induced activation of nuclear factor kappa-B (NF-kB) was significantly suppressed by $\mathrm{AC}$ treatment, as indicated by down-regulation of TLR4 and inhibition of the nuclear translocation of NF-кB p65 and by activation and degradation of the inhibitor of kappa B. These findings indicated that $\mathrm{AC}$ has a great potential to be developed as a therapeutic agent for human RA.

Keywords: rheumatoid arthritis, Anemone flaccida, Di Wu, anhuienoside C, inflammatory cytokines 


\section{INTRODUCTION}

Rheumatoid arthritis is an autoimmune disease marked by chronic inflammation and synovial proliferation, leading to the cartilage damage and joint destruction (Vincent et al., 2012). Although the exact etiology and pathogenesis of RA are unclear, the disease is characterized, in particular, by the involvement of numerous activated macrophages and FLSs in the inflammation of the synovial membrane and cartilage-pannus junction (GarciaCarbonell et al., 2016; Tang et al., 2016). These dysregulated immune cell interactions can induce the overproduction of proinflammatory cytokines such as IL- $1 \beta$, IL-6, and TNF- $\alpha$. It is reported that pro-inflammatory cytokines are activated by multiple signaling pathways, such as the MAPK and NF-кB pathways. In addition, exposure to pathogenic antigens such as LPS could induce TLR4 signaling pathway which subsequently induces NF- $\kappa \mathrm{B}$ activation and expression of pro-inflammatory cytokines such as TNF- $\alpha$, and IL-1 $\beta$, IL-6, resulting in an imbalance between pro-inflammatory and anti-inflammatory cytokine activity and contributes to the pathogenesis of RA (Fu et al., 2013; Zhu et al., 2016).

Nonsteroidal anti-inflammatory drugs are widely approved for the alleviation of pain as well as inflammatory and autoimmune components of the disease, without reducing the cartilage and bone destruction of joints. Unfortunately, NSAIDs may cause various side effects or toxicity, such as gastrointestinal disorders and cardiovascular risk (Desai et al., 2014). Biologics, including TNF- $\alpha$ inhibitors (infliximab and adalimumab), IL-1 $\beta$ inhibitors (anakinra), and IL-6 inhibitors (tocilizumab and atlizumab), represent a prominent group of drugs used in the treatment of RA, but their administration may cause side effects and can interfere with the immune defense responses. Furthermore, their high cost makes the access to these drugs prohibitive for the general public (Bevaart et al., 2010; Li et al., 2013). Thus, there is an urgent need to develop novel therapeutic agents.

Natural products, in addition to their traditional uses, have served as important sources of bioactive compounds that have played significant roles in drug discovery and development processes. Dry rhizomes of Anemone flaccida Fr. Schmidt (Ranunculaceae), commonly known as $D i W u$ in China, are widely used as a Chinese folk medicine for fractures and

Abbreviations: AC, anhuienoside C; AFS, Anemone flaccida crude triterpenoid saponins; BCA, bicinchoninic acid; CD68, differentiation 68; CFA, complete Freund's adjuvant; CIA, collagen-induced arthritis; CII, type II collagen; COX2, cyclooxygenase 2; DAPI, 4',6-diamidino-2-phenylindole; DMEM, Dulbecco's Modified Eagle's Medium; DMSO, dimethyl sulfoxide; ECL, chemiluminescence; ELISA, enzyme-linked immunosorbent assay; ERK, extracellular signal-regulated kinase; FBS, fetal bovine serum; FLSs, fibroblast-like synoviocytes; GAPDH, glyceraldehyde 3-phosphate dehydrogenase; H\&E, hematoxylin and eosin; IFA, incomplete Freund's adjuvant; IL- $\beta$, interleukin- $\beta$; IL-6, interleukin-6; iNOS, nitric oxide synthase; I $\mathrm{B} \alpha$, inhibitor of kappa B; JNK, Jun N-terminal kinase; LDH, lactate dehydrogenase; LPS, lipopolysaccharide; MAPK, mitogen-activated protein kinase; MMPs, matrix metalloproteinases; MTT, 3-[4,5-dimethylthiazol2-yl]-2,5-diphenyltetrazolium bromide; NF-kB, nuclear factor-kappaB; NMR, nuclear magnetic resonance; NO, nitric oxide; NSAIDs, nonsteroidal antiinflammatory drugs; PBS, phosphate-buffered saline; PVDF, polyvinylidene fluoride; RA, rheumatoid arthritis; SD, standard deviation; SDS-PAGE, sodium dodecyl sulfate-polyacrylamide gel electrophoresis; SPF, specific pathogen-free; TLR4, toll-like receptor 4; TNF- $\alpha$, tumor necrosis factor. to strengthen bones. Previous studies have demonstrated that triterpenoid saponins are the main chemicals and major bioactive constituents of this plant (Zhang et al., 2008; Han and Huang, 2009; Han et al., 2013). We have previously reported that crude triterpenoid saponins from A. flaccida ( $D i W u$ ) showed antiarthritic effects on type II CIA in rats. Furthermore, AC, a saponin compound isolated from A. flaccida, was observed to suppress the NO production in LPS-treated macrophage RAW 264.7 cells (Huang et al., 2014; Liu et al., 2015). Therefore, in the present study, we examined the anti-rheumatic effects of $\mathrm{AC}$ in a mouse model and evaluated the potential mechanisms involved.

\section{MATERIALS AND METHODS}

\section{Reagents}

Anhuienoside C (purity > 97\%; Figure 1) was isolated from dry rhizomes of A. flaccida, and the chemical structure was identified using ${ }^{1} \mathrm{H}-{ }^{1} \mathrm{H}$ correlation spectroscopy, heteronuclear single quantum coherence spectroscopy, heteronuclear multiple bond coherence, rotating-frame Overhauser spectroscopy, and ${ }^{1} \mathrm{H}$ and ${ }^{13} \mathrm{C}$ NMR analysis in our laboratory, as previously described (Huang et al., 2014). Dexamethasone used in mice was purchased from Guangdong Huanan Pharmaceutical Group Co., Ltd. (Guangzhou, China) and the dexamethasone was obtained from Aladdin (Shanghai, China). AC and dexamethasone were dissolved in distilled water. FBS, DMEM, and all other cell culture products were purchased from Life Technologies (Grand Island, NY, United States). Bovine CII, CFA (4 mg/mL), IFA (4 mg/mL), LPS (Escherichia coli 055:B5), and MTT were obtained from Sigma-Aldrich (St. Louis, MO, United States). LDH cytotoxicity detection kit was purchased from Jiancheng (Nanjing, China). TNF- $\alpha$, IL-1 $\beta$, and IL-6 ELISA kits were purchased from eBioscience (San Diego, CA, United States). Antibodies against inducible iNOS, phosphorylated (p)-p38, p38, p-ERK, ERK, p-c-JNK, JNK, p-IкB $\alpha$, I $\mathrm{B} \alpha$, NF-кB p65, and GAPDH were obtained from Cell Signaling Technology, Inc. (Beverly, MA, United States), Antibody against TLR4

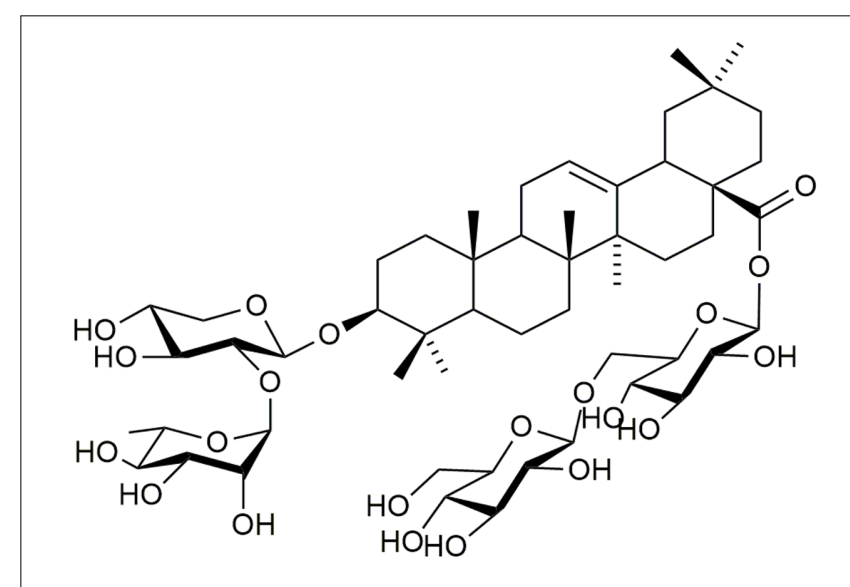

FIGURE 1 | Chemical structure of AC isolated from Anemone flaccida. 
was obtained from GeneTex (Irvine, CA, United States). A Pierce ${ }^{\mathrm{TM}}$ BCA protein assay kit was purchased from Thermo Fisher Scientific, Inc. (Rockford, IL, United States). The murine macrophage cell line RAW 264.7 (ATCC TIB- ${ }^{\mathrm{TM}}$ ) was purchased from American Type Culture Collection (Manassas, VA, United States).

\section{Animals}

Male DBA/1J mice (6- to 8-week-old), SPF grade, certified [No. SCXK (Shanghai) 2012-0002] were purchased from Shanghai SLAC Laboratory Animal Co., Ltd. (Shanghai, China). All mice were allowed to acclimate for 1 week before the experiments were started. The animals were maintained under SPF conditions at approximately $23 \pm 1^{\circ} \mathrm{C}$ with a 12 -h light/dark cycle and were given a standard diet and water ad libitum. All experimental procedures complied with the Guide for the Care and Use of Laboratory Animals and were approved by the local Animal Ethics Committee of Jinan University.

\section{Induction of Arthritis and Drug Administration}

Experimental arthritis was induced in mice as described previously (Wen et al., 2012; Li et al., 2013). Briefly, 60 animals were randomly divided into the following six groups ( $n=10$ each): normal control; CIA; CIA + AC (20 mg/kg/day); $\mathrm{CIA}+\mathrm{AC}(30 \mathrm{mg} / \mathrm{kg} /$ day $) ; \mathrm{CIA}+\mathrm{AC}(40 \mathrm{mg} / \mathrm{kg} /$ day $)$, and $\mathrm{CIA}+$ dexamethasone $(0.2 \mathrm{mg} / \mathrm{kg} /$ day $)$. Bovine CII was dissolved in $0.05 \mathrm{M}$ acetic acid $(2.0 \mathrm{mg} / \mathrm{mL})$ and completely emulsified with CFA at a ratio of $1: 1$. The mice were immunized by intradermal injection of $100 \mu \mathrm{g}$ of CII in CFA into the base of the tail. The day of the first immunization was defined as day 1 . The second injection was administered on day 21 with an equal amount of CII emulsified in IFA. The CII solution and emulsions with CFA and IFA were always freshly prepared. On day 28 after the initial immunization, we used LPS (50 $\mu \mathrm{g} / \mathrm{mouse}$ ) to boost the arthritis incidence and severity, as previously reported (You et al., 2006; Wen et al., 2012). The mice in the normal control group did not receive the injection. To determine the effect of AC treatment on the onset of CIA, mice with a score of 2-4 were randomly divided into five equal cohorts 1 day after the LPS treatment, and AC administration was started. The mice in the AC treatment groups received an intragastric dose of AC $(20,30$, or $40 \mathrm{mg} / \mathrm{kg} /$ day $)$ for 21 days, while the positive control group received dexamethasone $(0.2 \mathrm{mg} / \mathrm{kg} /$ day $)$. The CIA and normal control groups were administered an equal volume of saline. Following the LPS challenge, the degree of arthritis was examined every 3 days. Meanwhile, the body weight of the mice was measured every 3 days, and changes in body weight were monitored. Arthritis symptoms were graded using a scoring system as previously described, with the maximum clinical score of 16 per mouse (Brand et al., 2007). The severity of arthritis was expressed as the mean arthritic index on a $0-4$ scale according to the following criteria: 0 , no edema or swelling; 1, swelling and erythema of one digit; 2 , swelling and erythema of more than two digits or that limited to the foot; 3 , slight edema and erythema from the ankle to the tarsal bone; and 4, severe edema and erythema involving the entire hind paw or forepaw. Thereafter, the mice were closely monitored and scored on alternate days in a blinded manner for signs of arthritis severity.

\section{Spleen Index Assay}

The spleens were promptly removed and weighed when the animals were sacrificed on day 51 after the primary immunization. The spleen index was expressed as a ratio calculated as follows: ratio $(\mathrm{mg} / \mathrm{g})=$ spleen weight $(\mathrm{mg}) /$ body weight $(\mathrm{g}) \times 10^{3}$.

\section{Histological Analysis of Paws}

On day 51, all mice were sacrificed. The forepaws and hind paws were surgically removed and skinned. The right hind paws were fixed in $4 \%$ buffered formaldehyde, then decalcified in $12 \%$ disodium ethylenediaminetetraacetic acid for 1 month, dehydrated, and embedded in paraffin. Sections were cut along the longitudinal axis, mounted, and stained with H\&E.

\section{Immunohistochemical Staining of Joint Tissues}

For the quantitative analysis of macrophage infiltration and local TNF- $\alpha$ accumulation in joint tissue, commercially available monoclonal TNF- $\alpha$ and cluster of CD68 antibodies were used. Three slices were individually taken from each mouse, and four vision fields were randomly observed at a high magnification $(\times 100)$.

\section{Cell Culture}

RAW 264.7 cells were maintained in DMEM supplemented with $100 \mathrm{U} / \mathrm{mL}$ penicillin, $100 \mu \mathrm{g} / \mathrm{mL}$ streptomycin, $10 \%$ heatinactivated FBS, $2 \mathrm{mM}$ glutamine, $1 \mathrm{mM}$ sodium pyruvate, and $4.5 \mathrm{~g} / \mathrm{L}$ glucose at $37^{\circ} \mathrm{C}$ in a humidified atmosphere containing $5 \% \mathrm{CO}_{2}$.

\section{LDH and MTT Assay}

To determine the cytotoxicity of AC and dexamethasone, RAW 264.7 cells $\left(5 \times 10^{3}\right.$ cells/well $)$ were seeded in a 96well plate containing DMEM supplemented with 10\% FBS and incubated for $24 \mathrm{~h}$ until the cells were nearly confluent. AC and dexamethasone was added at different concentrations (10, 20, 40 , and $80 \mu \mathrm{M})$ with or without LPS $(100 \mathrm{ng} / \mathrm{mL})$ to the cell culture medium, and the plate was incubated for an additional $24 \mathrm{~h}$. The cells were centrifuged at $12,000 \mathrm{rpm}$ for $4 \mathrm{~min}$ at room temperature. Then culture medium was carefully removed from each well in order to determine $\mathrm{LDH}$ activity by using an $\mathrm{LDH}$ cytotoxicity detection kit according to the protocol of the manufacturer. The absorbance of each well was measured at $490 \mathrm{~nm}$ using a microplate reader (Synergy HT; BioTek, United States). The relative $\mathrm{LDH}$ release is defined by the ratio of $\mathrm{LDH}$ released over total $\mathrm{LDH}$ in untreated cells. For the analysis of cell viability, cells was treated with the indicated various concentrations $(10,20,40$, and $80 \mu \mathrm{M})$ of AC or dexamethasone with or without LPS (100 ng/mL) for $24 \mathrm{~h}$. The cells were washed twice with PBS and incubated with $30 \mu \mathrm{L}$ of MTT $(5 \mathrm{mg} / \mathrm{mL})$ for $4 \mathrm{~h}$ at $37^{\circ} \mathrm{C}$. The supernatant was discarded, and $100 \mu \mathrm{L}$ of DMSO 
was added. After 15 min of incubation, absorbance was measured at $570 \mathrm{~nm}$ in a microplate reader (Synergy HT; BioTek, United States).

\section{Quantitative Real-Time Polymerase Chain Reaction Assay}

Quantitative real-time polymerase chain reaction (PCR) was performed to determine whether AC regulated the mRNA expression of iNOS, COX-2, TNF- $\alpha$, IL-1 $\beta$, and IL-6 in RAW 264.7 cells following exposure to LPS (100 ng/mL) for $3 \mathrm{~h}$. RAW 264.7 murine macrophages were pretreated with AC at different concentrations for $2 \mathrm{~h}$ before stimulation with $100 \mathrm{ng} / \mathrm{mL}$ LPS. After the incubation for an additional $3 \mathrm{~h}$, total RNA was extracted using the TRIzol reagent (Invitrogen, Carlsbad, CA, United States), then quantified, and reverse-transcribed to cDNA. Relative quantitation of expression of the selected genes was performed in a LightCycler 480 system (Roche, Pleasanton, CA, United States) using a SYBR Green PCR master mix reagent kit (Takara, Dalian, China) and the PCR primers shown in Table 1. The cycling conditions were $95^{\circ} \mathrm{C}$ for $30 \mathrm{~s}$, followed by 40 cycles of $95^{\circ} \mathrm{C}$ for $10 \mathrm{~s}, 57^{\circ} \mathrm{C}$ for $10 \mathrm{~s}$, and $72^{\circ} \mathrm{C}$ for $10 \mathrm{~s}$. A dissociation curve was generated in a cycle of $95^{\circ} \mathrm{C}$ for $5 \mathrm{~s}$, $67^{\circ} \mathrm{C}$ for $1 \mathrm{~min}$, and $97^{\circ} \mathrm{C}$ for $15 \mathrm{~s}$. The mRNA expression levels were determined relative to the blank control after normalization to the GAPDH level using the $2^{-\Delta \Delta C_{t}}$ method. Analysis was carried out in triplicates. Control cells were grown under identical conditions without AC and LPS. In addition, RAW 264.7 cells were incubated under identical conditions in the absence of LPS with $\mathrm{AC}(40 \mu \mathrm{M})$ alone.

\section{Measurement of TNF- $\alpha$, IL-1 $\beta$, and IL- 6 levels in RAW 264.7 Cells}

The effect of AC on the cytokine (TNF- $\alpha$, IL-1 $\beta$, and IL-6) release from RAW 264.7 cells was evaluated using ELISA assays. Briefly, RAW 264.7 murine macrophages $\left(5 \times 10^{5}\right.$ cells/well $)$ were cultured in a 6-well microplate for $24 \mathrm{~h}$. The cells were pretreated with varying concentrations of $\mathrm{AC}$ for $1 \mathrm{~h}$ before stimulation with $100 \mathrm{ng} / \mathrm{mL}$ LPS. The activated cells were incubated for

TABLE 1 | Primers Used for Real-Time PCR.

\begin{tabular}{|c|c|c|c|}
\hline Gene name & & Primer sequence $\left(5^{\prime}-3^{\prime}\right)$ & Product \\
\hline \multirow[t]{2}{*}{ IL-1 $1 \beta$} & Forward & GAAATGCCACCTTITGACAGTG & 116 \\
\hline & Reverse & TGGATGCTCTCATCAGGACAG & \\
\hline \multirow[t]{2}{*}{ IL-6 } & Forward & TAGTCCTTCCTACCCCAATTTCC & 76 \\
\hline & Reverse & TTGGTCCTTAGCCACTCCTTC & \\
\hline \multirow[t]{2}{*}{ COX-2 } & Forward & TTCAACACACTCTATCACTGGC & 271 \\
\hline & Reverse & AGAAGCGTTTGCGGTACTCAT & \\
\hline \multirow[t]{2}{*}{ iNOS } & Forward & GGAGTGACGGCAAACATGACT & 127 \\
\hline & Reverse & TCGATGCACAACTGGGTGAAC & \\
\hline \multirow[t]{2}{*}{ TNF- $\alpha$} & Forward & GGGCCACCACGCTCTTC & 104 \\
\hline & Reverse & GGTCTGGGCCATAGAACTGATG & \\
\hline \multirow[t]{2}{*}{ GAPDH } & Forward & AGGTCGGTGTGAACGGATTTG & 123 \\
\hline & Reverse & TGTAGACCATGTAGTTGAGGTCA & \\
\hline
\end{tabular}

another $6 \mathrm{~h}$ to measure the TNF- $\alpha$, IL-1 $\beta$, and IL- 6 secretion. The supernatants were collected, and the concentrations of TNF- $\alpha$, IL- $1 \beta$, and IL- 6 were determined using specific ELISA kits according to the manufacturer's protocols.

\section{Western Blot Analysis}

RAW 264.7 cells $\left(1.6 \times 10^{6}\right.$ cells/well $)$ were seeded in a $100-\mathrm{mm}$ dish for $24 \mathrm{~h}$ and then pretreated with varying concentrations of AC (10-40.0 $\mu \mathrm{M})$ for $2 \mathrm{~h}$, followed by LPS stimulation for $30 \mathrm{~min}$. The cells were washed twice with ice-cold PBS, collected, lysed, and then centrifuged at $14,000 \times g$ for $15 \mathrm{~min}$ at $4^{\circ} \mathrm{C}$. The supernatant was collected, and protein concentrations were determined by the BCA protein assay. Total protein samples $(20 \mu \mathrm{g})$ were separated by $8 \%(\mathrm{w} / \mathrm{v})$ SDS-PAGE and transferred onto a PVDF membrane (Millipore, Billerica, MA, United States). All membranes were incubated for $1 \mathrm{~h}$ at room temperature with 5\% (w/v) skim milk in Tris-buffered saline with Tween 20 (TBST) to block non-specific binding and then incubated overnight at $4^{\circ} \mathrm{C}$ with specific rabbit polyclonal antibodies $(1: 1,000)$ recognizing iNOS, p-ERK, ERK, p-JNK, JNK, p-p38, $\mathrm{p} 38, \mathrm{p}-\mathrm{I} \kappa \mathrm{B} \alpha, \mathrm{I} \kappa \mathrm{B} \alpha$, and TLR4. The blots were rinsed three times with TBST buffer for 5 min and subsequently incubated with a goat anti-rabbit IgG horseradish peroxidase-conjugated secondary antibody for $2 \mathrm{~h}$ at room temperature. The signals were detected using an enhanced ECL system (Bio-Rad, Hercules, CA, United States) according to the manufacturer's instructions.

\section{Detection of NF-кB Nuclear Translocation by Immunofluorescent Staining}

RAW 264.7 cells $\left(2 \times 10^{4}\right.$ cells $\left./ \mathrm{mL}\right)$ were cultured in $15-\mathrm{mm}$ culture dishes for $24 \mathrm{~h}$ and pretreated with $\mathrm{AC}$ for $2 \mathrm{~h}$ prior to treatment with $100 \mathrm{ng} / \mathrm{mL}$ LPS for $30 \mathrm{~min}$. The cells were fixed, permeabilized, and immunostained with the anti-NF- $\mathrm{B}$ p65 antibody and then with the secondary anti-goat antibody. Nuclear staining was visualized with DAPI (Sigma, St. Louis, MO, United States). Fluorescence signals were recorded using a confocal laser scan microscope LSM 510 (Zeiss, Germany).

\section{Statistical Analysis}

Data are reported as the mean $\pm \mathrm{SD}$ from three or more experiments using the GraphPad Prism 5.0 statistical package. The Student's $t$-test and one-way analysis of variance were used for parametric analysis to compare groups and perform multigroup comparisons. The Mann-Whitney $U$-test was used to analyze non-parametric data. A $P$-value of less than 0.05 was considered to be statistically significant, and a $P$-value of less than 0.01 was considered very significant.

\section{RESULTS}

\section{Effects of AC on RA Symptoms and Body Weight in CIA Mice}

The anti-arthritic effects of AC on the progression of LPSenhanced arthritis development were assessed in mice with CIA. 
The CIA mice developed severe swelling, redness, erythema, and joint rigidity of the forepaws and hind paws. In contrast, administration of $\mathrm{AC}(20,30$, and $40 \mathrm{mg} / \mathrm{kg} /$ day $)$ significantly blocked the progression of arthritis development, and according to the mean arthritis scores, the severity of CIA was significantly attenuated by AC (Figure 2A).

Along with the development of arthritis, the relationship between the extent of paw swelling and the weight loss was investigated. As shown in Figure 2B, the AC treatment enhanced the body weight of the CIA mice, followed by a normal weight gain in the subsequent weeks, whereas the dexamethasonetreated mice showed a significant weight loss.

\section{Effects of AC on Spleen Index}

The spleen index is associated with immunological functions. As shown in Figure 3, the spleen index of the CIA group increased compared with that of the normal control group. The treatment with various concentrations of $\mathrm{AC}(20,30$ and $40 \mathrm{mg} / \mathrm{kg})$ resulted in significant decreases of the spleen index.

\section{AC Treatment Decreased Immune-Mediated Inflammation and Joint Damage in CIA Mice}

Upon LPS treatment, severe cartilage and bone erosions, accompanied by large amounts of inflammatory cell infiltration

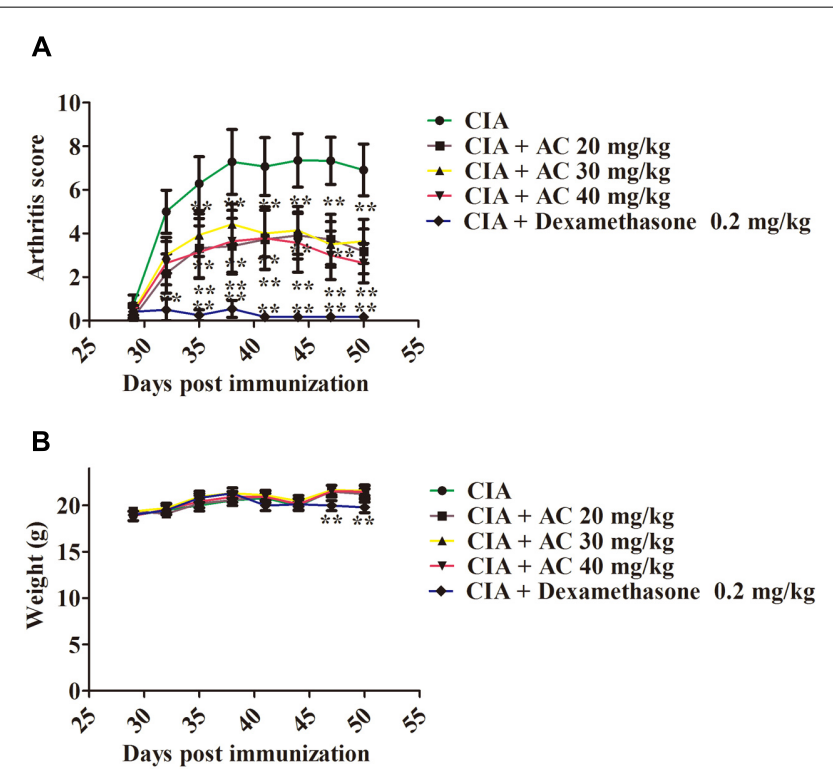

FIGURE 2 | The effect of AC on CIA mice. (A) AC treatment ameliorates the paw edema volume and redness compared with those in the CIA mice. AC was administered intragastrically 1 day after LPS treatment (day 29 of the initial immunization) and every days thereafter until day 50 . Mice receiving dexamethasone $(0.2 \mathrm{mg} / \mathrm{kg})$ were used as a positive control group. The clinical score was used to evaluate the progression of arthritis development. ${ }^{*} P<0.05,{ }^{*} P<0.01$ for the treatment groups vs. the CIA group. (B) Body weight changes in mice. The data are expressed as the mean $\pm \operatorname{SD}(n=10)$. ${ }^{* *} P<0.01$ for the dexamethasone treatment group vs. the CIA group.

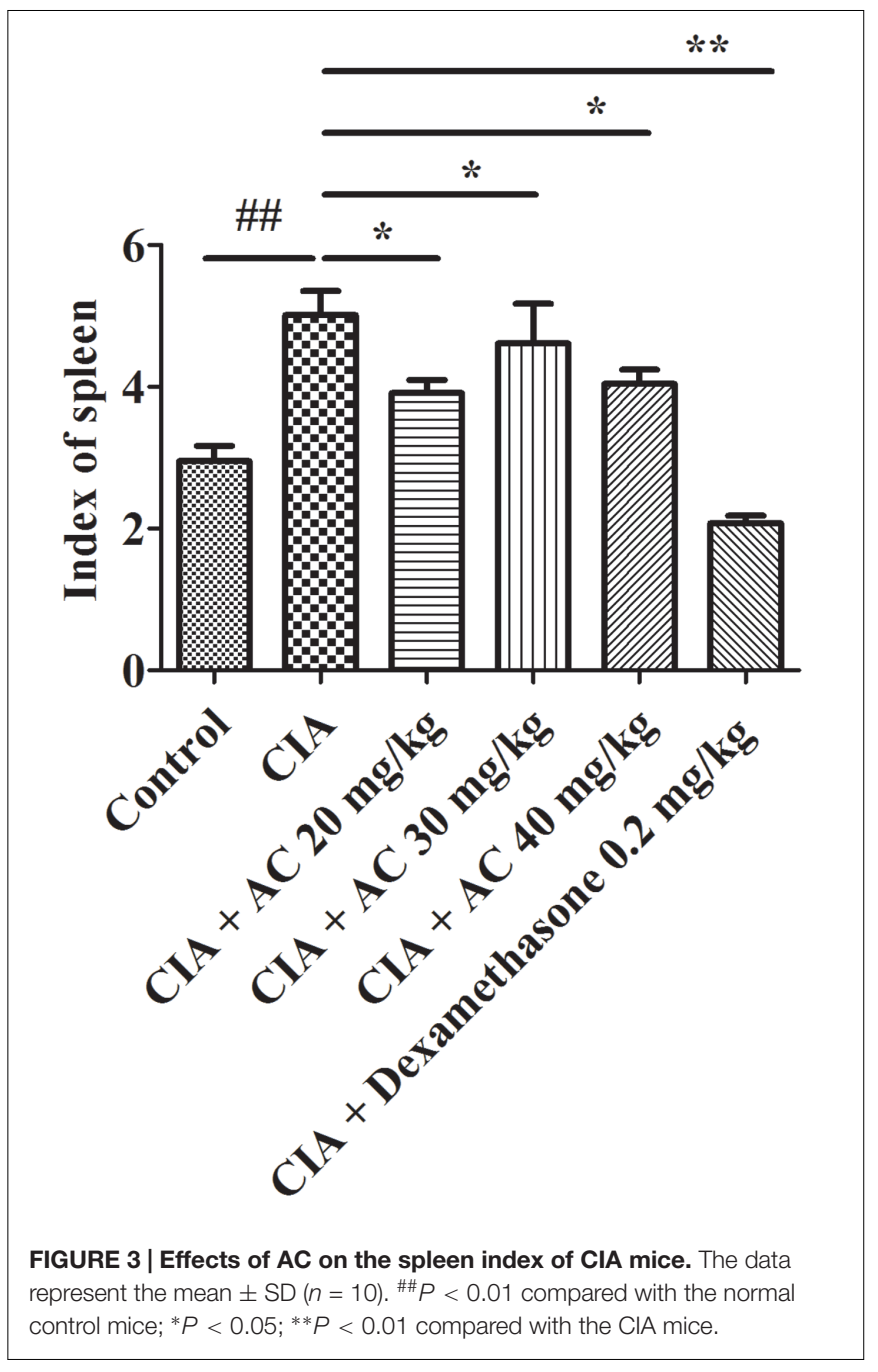

and pannus formation, were observed in the sections obtained from the CIA mice (Figure 4). In contrast, treatment with AC suppressed these changes, and the joint space was almost completely preserved in the AC-treated mice (Figure 4A). Development of arthritis in the CIA mice was associated with the increased numbers of macrophages and overproduction of TNF- $\alpha$ compared to these parameters in the normal control mice. AC significantly suppressed the TNF- $\alpha$ production in joint tissues as revealed by immunohistochemical staining (Figure $4 \mathrm{~B}$ ). The effective treatment consistently correlated with the reduction of CD68-positive macrophages. To further explain the anti-arthritis effects of AC, we investigated the macrophage population changes in joint tissue. As shown in Figure 4C, compared with the normal control mice, the number of CD68-positive cells increased in the synovium of the CIA group, while significantly decreased in that of the AC-treated group.

\section{AC Does Not Affect Growth of RAW 264.7 Cells}

To examine the cytotoxicity of AC, the LDH and MTT assay were used to evaluate the growth of RAW 264.7 cells. 


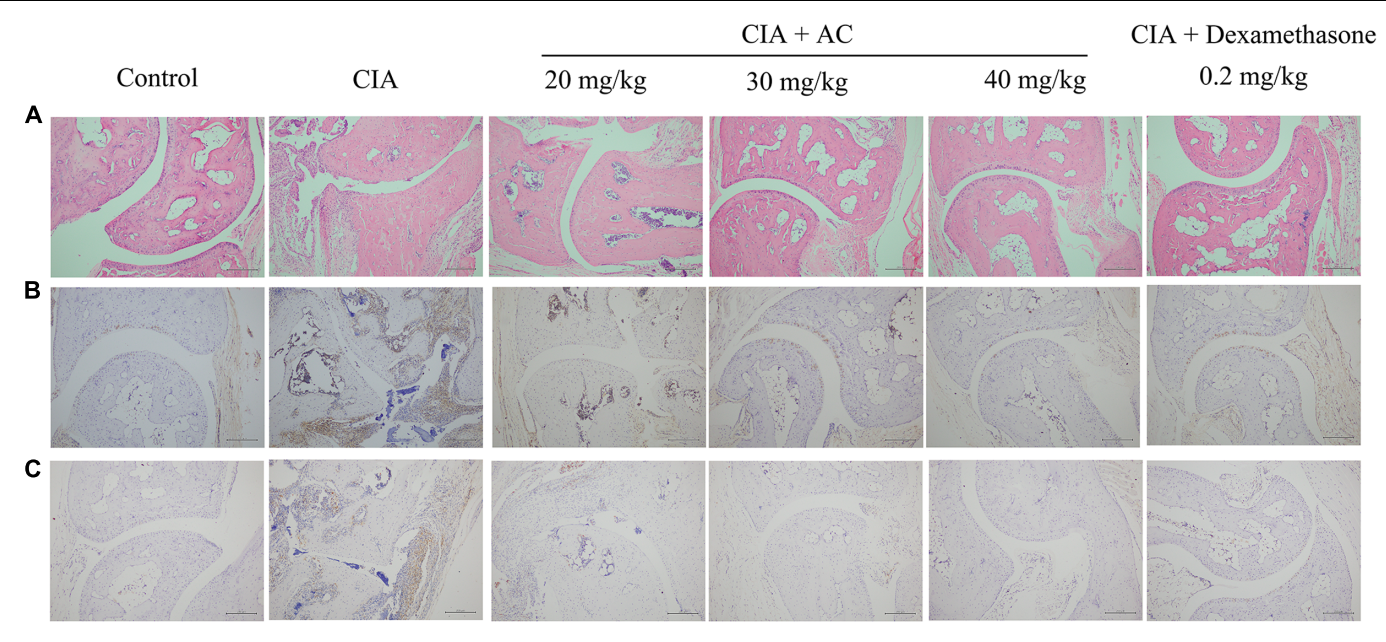

FIGURE 4 | Progression of LPS-enhanced arthritis was blocked by treatment with AC. Male DBA/1J mice were immunized with Cll, and LPS was administered on day 28 to induce LPS-enhanced CIA as described in "Materials and Methods." (A) Histological evaluations of anti-arthritis effects of AC were performed using joint slides stained with H\&E (original magnification $\times 100$ ). (B) TNF- $\alpha$ expression in the joint on day 51 was evaluated by immunohistochemical staining (original magnification $\times 100$ ). (C) Immunohistochemical analysis of CD68 was performed on sections of the ankle joint from healthy mice and CIA mice treated with vehicle or AC (original magnification $\times 100)$.

As shown in Figure 5, treatment with 10, 20, or $40 \mu \mathrm{M}$ AC for $24 \mathrm{~h}$ had no significant effect on the cell viability; however, $80 \mu \mathrm{M}$ AC decreased the cell viability by $20 \%$. While dexamethasone exhibited significant inhibitory effect on cell viability at concentrations of above $20 \mu \mathrm{M}$. Based on these data, the three concentrations of $\mathrm{AC}(10,20$, and $40 \mu \mathrm{M})$ that failed to be cytotoxic to RAW 264.7 cells were used in subsequent experiments.

\section{Effects of AC on LPS-Induced Expression of iNOS and COX-2 in RAW 264.7 Cells}

Nuclear factor-kappaB has been shown to mediate the production of the pro-inflammatory mediators iNOS and COX-2 by synoviocytes (Kunanusornchai et al., 2016; Wu et al., 2016b; Yang et al., 2016). Based on these data, we examined the effects of AC on the mRNA expression levels of iNOS and COX-2. As shown in Figure 6A, AC significantly inhibited the COX-2 and iNOS mRNA expression in a dose-dependent manner. Further, it was found that AC significantly inhibited the protein expression level of iNOS in a dose-dependent manner (Figure 6B).

\section{Effects of AC on mRNA Expression and Secretion Levels of TNF- $\alpha$, IL-1 $\beta$, and IL-6 in RAW 264.7 Cells}

It is well known that pro-inflammatory cytokines play crucial roles in the pathogenesis of RA. To examine the antiinflammatory effect of AC, we evaluated the mRNA expression levels of cytokines produced in LPS-induced RAW 264.7 cells. As shown in Figure 7A, the mRNA expression levels of TNF- $\alpha$, IL-1 $\beta$, and IL-6 significantly increased after LPS stimulation. Following AC treatment, the LPS-triggered TNF- $\alpha$, IL- $1 \beta$, and IL-6 expression was dose-dependently inhibited.
Enzyme-linked immunosorbent assays were used to evaluate the effect of AC on the secretion of pro-inflammatory cytokines by LPS-treated RAW 264.7 cells. Consistent with the changes in the mRNA expression levels, AC dose-dependently inhibited the secretion of TNF- $\alpha$, IL-1 $\beta$, and IL-6 (Figure 7B). In particular, the TNF- $\alpha$ production decreased to $1.81 \mathrm{ng} / \mathrm{mL}$ at an AC concentration of $40 \mu \mathrm{M}$ compared to $7.34 \mathrm{ng} / \mathrm{mL}$ in LPS-treated RAW 264.7 cells. The results of this experiment were consistent with those of the animal experiments, in which AC significantly suppressed the TNF- $\alpha$ production in joint tissues.

\section{Effect of AC on Activation of Mitogen-Activated Protein Kinase Signaling Pathways in LPS-Stimulated RAW 264.7 Cells}

It has been reported that stimulation of RAW 264.7 macrophages with LPS results in the activation of MAPKs, including ERK, p38, and JNK (Kumar et al., 2016). We next investigated whether AC modulated these signaling proteins in LPS-induced RAW 264.7 cells. As shown in Figure 8 and Supplementary Figure $S 1$, the results indicated that $\mathrm{AC}(10,20$, and $40 \mu \mathrm{M})$ dosedependently attenuated the LPS-stimulated phosphorylation of ERK. Similarly, AC showed a strong inhibitory effect on the phosphorylation of JNK and p38 MAPK in response to LPS stimulation (Figure 8).

\section{Effects of AC on TLR4 and NF- $k B$ Nuclear Translocation in LPS-Induced RAW 264.7 Cells}

TLR4 signaling plays an important role in inflammatory response. Activation of TLR4 by LPS induces NF-кB and MAPKs activation in RAW264.7 cells exposed to LPS (Huang and Pope, 

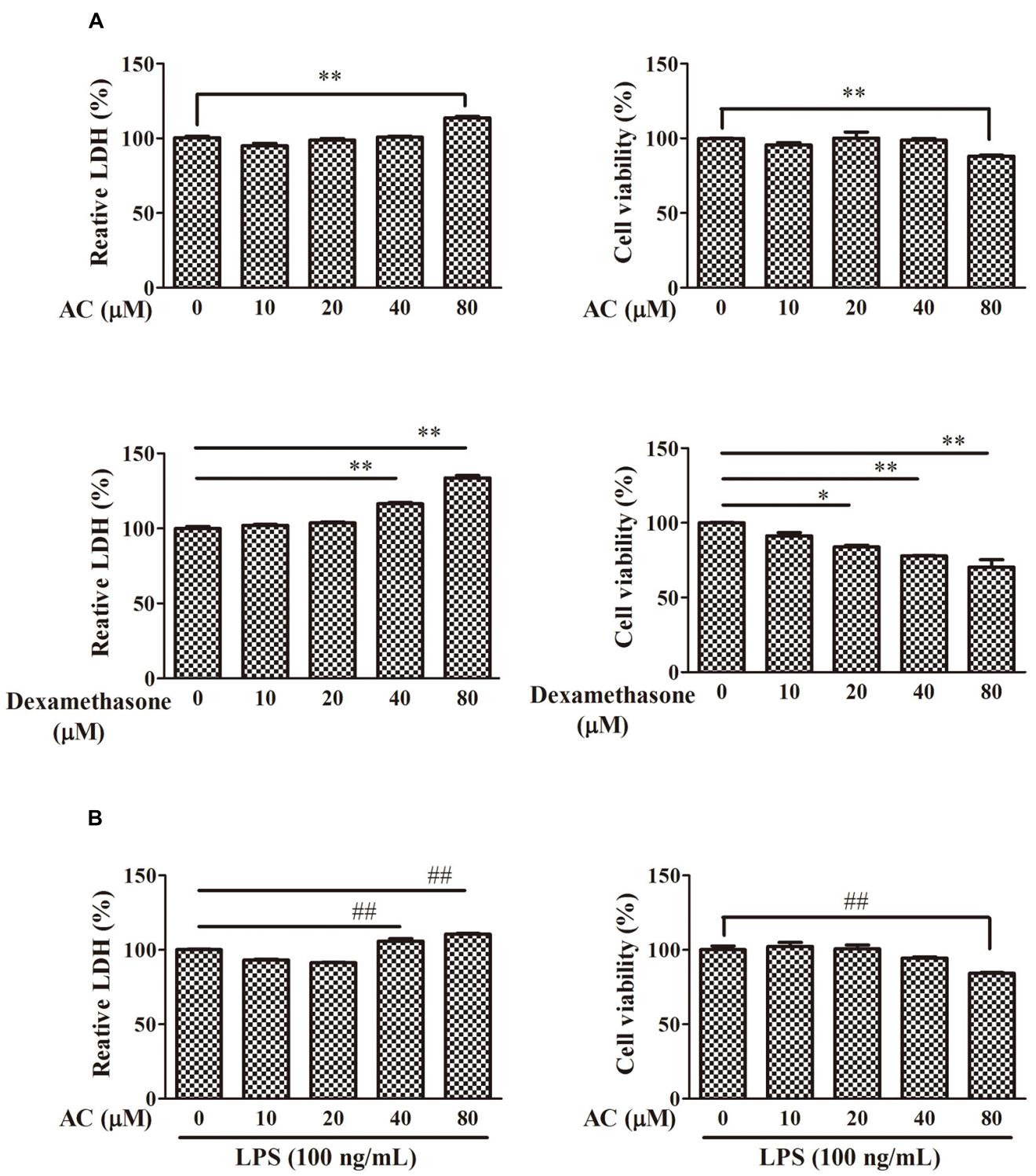

Dexamethasone

$(\mu \mathrm{M})$
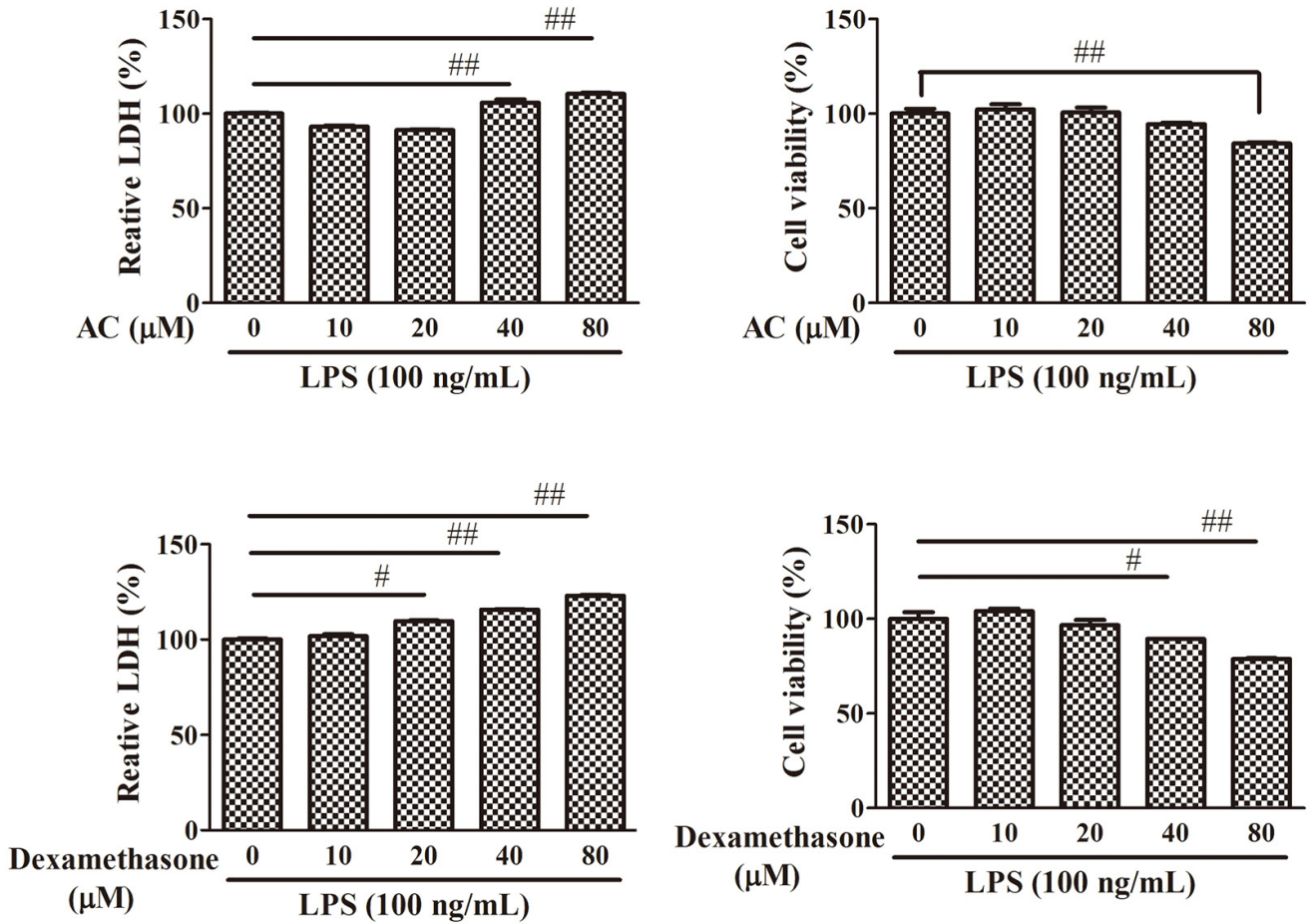

FIGURE 5 | Effects of AC and dexamethasone on the growth of RAW 264.7 cells. (A) Cells were incubated in a complete medium with the indicated concentrations of $A C$ and dexamethasone for $24 \mathrm{~h}$, and cell viability was measured by the LDH and MTT assay. (B) Macrophages were treated with AC and dexamethasone (10, 20, 40, and $80 \mu \mathrm{M})$ and exposed to LPS (100 $\mathrm{ng} / \mathrm{mL})$ for $24 \mathrm{~h}$. Cellular viability was measured using the LDH and MTT assay. Each value represents the mean $\pm \mathrm{SD}$ of three independent experiments. ${ }^{*} P<0.05$, ${ }^{* *} P<0.01$ compared with the control group; ${ }^{\#} P<0.05$, ${ }^{\# \#} P<0.01$ compared with the LPS-treated group. 

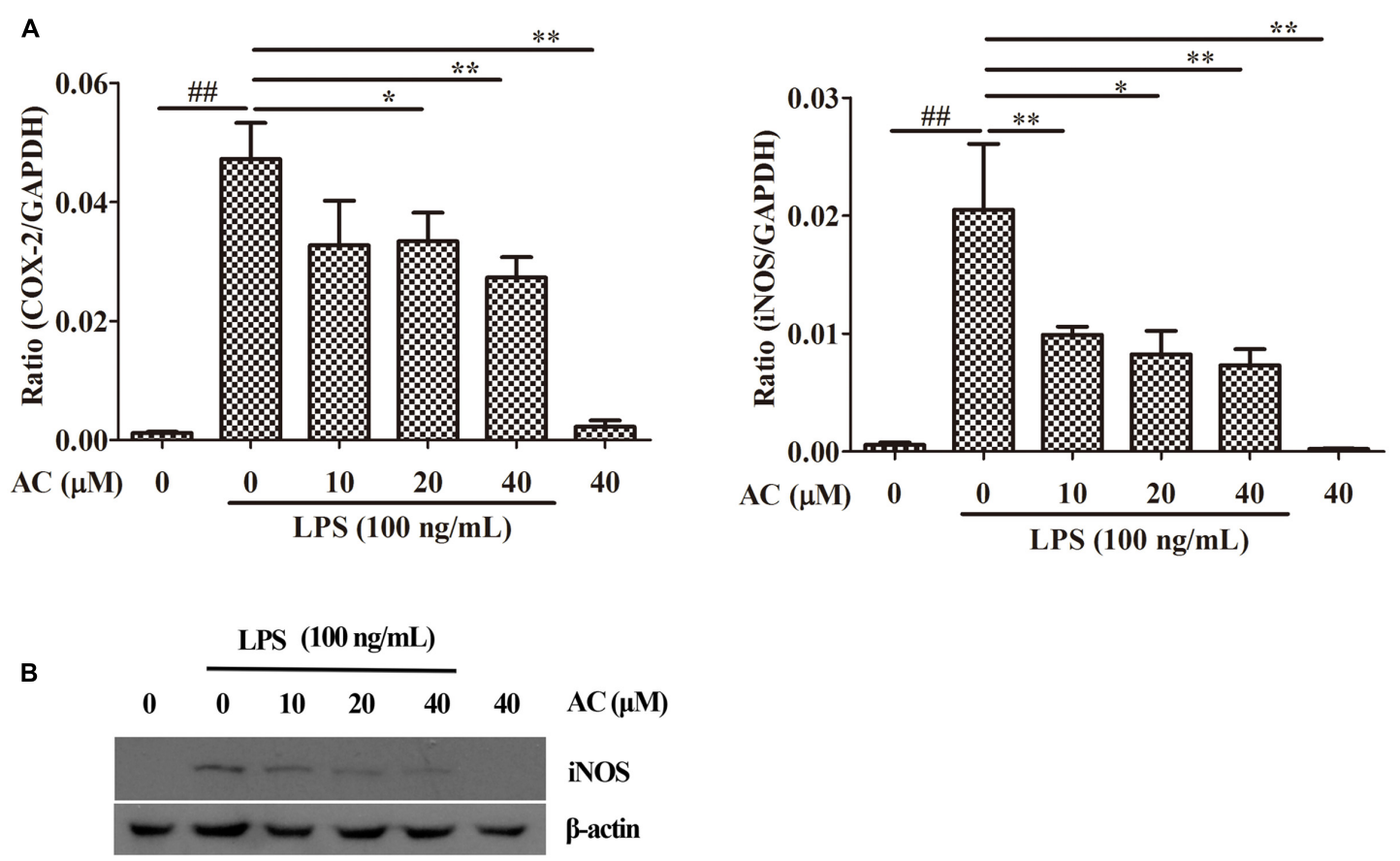

FIGURE 6 | Effects of AC on iNOS and COX-2 in RAW 264.7 cells. (A) Cells were pretreated with AC (10, 20, and 40 $\mu$ M) for $2 \mathrm{~h}$ and stimulated with LPS $(100 \mathrm{ng} / \mathrm{mL})$ for $3 \mathrm{~h}$. The mRNA expression levels of iNOS and COX-2 were measured by real-time PCR. (B) Western blot analysis of the expression level of iNOS. Data were obtained from three independent experiments and are expressed as the mean $\pm \mathrm{SD}$. ${ }^{\#} P<0.05$, ${ }^{\#} P<0.01$ for the LPS-treated group vs. the normal control group; ${ }^{*} P<0.05,{ }^{* *} P<0.01$ for the treatment groups vs. the LPS-treated group.
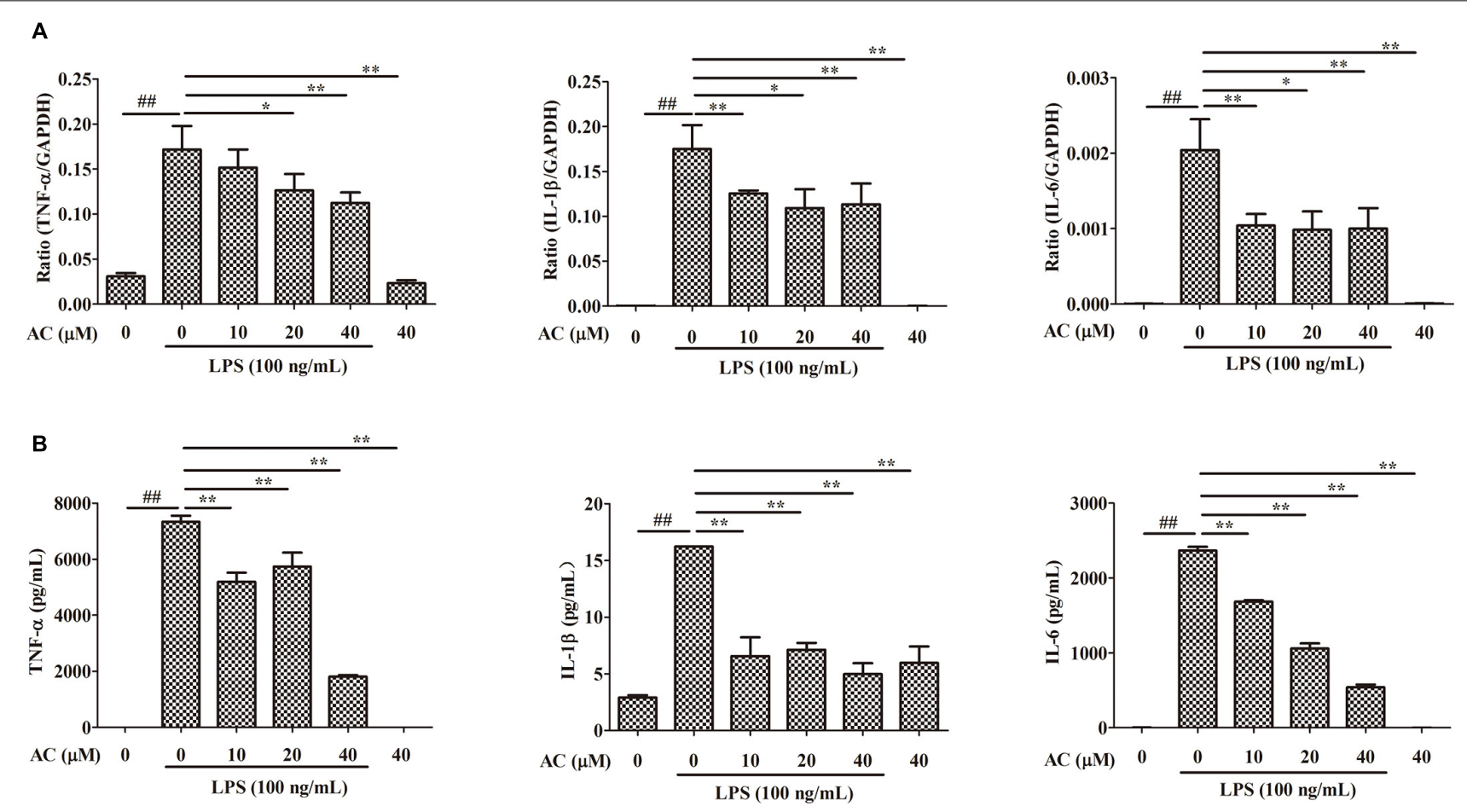

FIGURE 7 | Inhibitory effects of AC on (A) mRNA expression and (B) secretion of TNF- $\alpha$, IL-1 $\beta$, and IL-6 in LPS-induced RAW 264.7 cells. Data were obtained from three independent experiments and are expressed as the mean $\pm \mathrm{SD}$. ${ }^{\#} P<0.05,{ }^{\# \#} P<0.01$ for the LPS-treated group vs. the normal control group;

${ }^{*} P<0.05,{ }^{* *} P<0.01$ for the treatment groups vs. the LPS-treated group. 


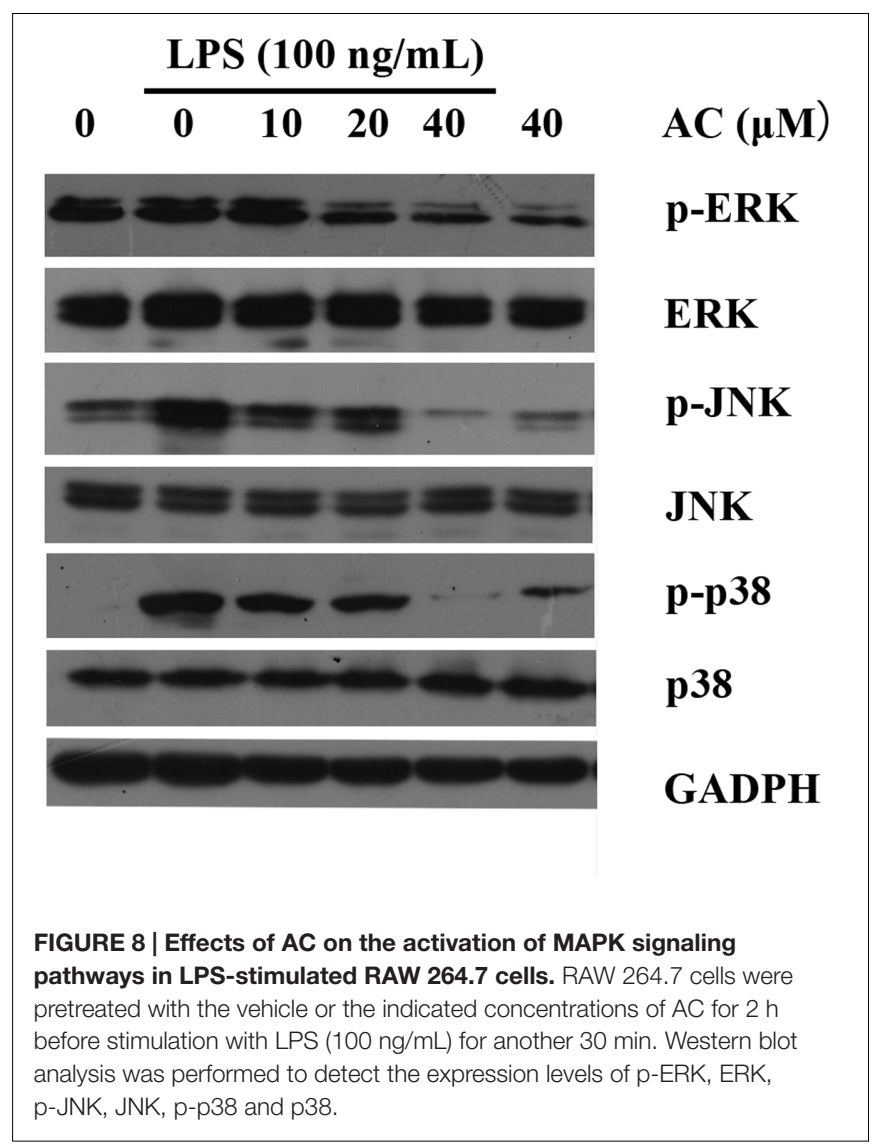

2009; Wu et al., 2016a). Therefore, the expression level of TLR4 was detected by western blot analysis. The result showed that AC significantly decreased the expression of TLR4 in a dosedependent manner (Figure 9B).

Nuclear factor-kappaB is a key transcriptional regulator in immune and inflammatory responses, and it regulates the production of several cytokines, including TNF- $\alpha$, IL- $1 \beta$, and IL-6 (Mu et al., 2016). Therefore, we hypothesized that the anti-inflammatory effects of AC might be associated with the NF-кB pathway. To confirm this hypothesis, we used immunofluorescence staining to determine the NF- $\kappa$ B activity. As shown in Figure 9A, the immunofluorescence images revealed that the basal NF- $\kappa \mathrm{B}$ p 65 was distributed in the cytoplasm of RAW 264.7 cells, while nuclear translocation of p65 increased after LPS stimulation. In contrast, this translocation was dosedependently inhibited by AC treatment, and no obvious change in the NF- $\mathrm{B}$ activity was observed in the presence of $\mathrm{AC}(40 \mu \mathrm{M})$ alone. NF- $\kappa$ B translocation into the nucleus is preceded by the phosphorylation, ubiquitination, and proteolytic degradation of Iк $\mathrm{B} \alpha$ (Torices et al., 2015). To determine whether the inhibitory action of AC on LPS-induced NF- $\mathrm{B}$ activation was due to its effect on I $\kappa \mathrm{B} \alpha$ degradation, we determined the expression and phosphorylation levels of cytoplasmic I $\mathrm{I} \alpha \alpha$ by the western blot assay. The results showed that the LPS-induced activation of I $\mathrm{B} \alpha$ was significantly inhibited by $\mathrm{AC}$ treatment (Figure 9B). In addition, a significant decrease of the expression level of $\mathrm{I} \kappa \mathrm{B} \alpha$ was observed in LPS-induced RAW 264.7 cells, while it increased dose-dependently in the presence of AC.

\section{DISCUSSION}

Macrophages are found in large numbers throughout the synovium of RA patients. Macrophage-derived cells, named type A synoviocytes, constitute part of the healthy synovial lining; however, numerous activated macrophages of other subtypes are accumulated in the synovial inflammatory infiltrate and pannuscartilage interface. Activated macrophages produce many proinflammatory mediators, including TNF- $\alpha$, IL-6, and IL-8, as well as tissue-degrading enzymes, which contribute to the inflammatory response and bone destruction. Furthermore, the number of synovial macrophages, as indicated by the expression of CD68, has been found to correlate with joint erosion in RA (Udalova et al., 2016; Yeo et al., 2016). In this study, the number of CD68-positive macrophages significantly increased in synovial tissues of CIA mice and strongly decreased in AC-treated CIA mice in a dose-dependent manner (Figure 4).

Nitric oxide is synthesized by the iNOS enzyme, and iNOS and COX-2 are often co-expressed in inflammatory tissues (Figure 6B). Excessive production of $\mathrm{NO}$ and COX-2 can lead to a simultaneous release of prostaglandin E2 (PGE2) in degenerative and inflammatory arthritis. In our previous study, AFS was found to show anti-arthritic effects on type II CIA in rats. We have determined that $\mathrm{AC}$ significantly inhibited the NO production by LPS-stimulated macrophage cell lines as well. Among the main active constituents of AFS, AC showed the strongest anti-inflammatory activity (Huang et al., 2014). Thus we thought AC was superior to the other compounds and examined anti-rheumatic effects of AC in a mouse model in the present study. It could be deduced from the structures of all these six tested compounds that they might act through the same target, since they are all triterpenoid saponins with similar substituent glycosyl group(s). The difference in anti-inflammatory activity might be due to the steric hindrance of glycosyl group(s) and the numbers of H-bond formed between the glycosyl group(s) and its target. It would be worthy that although the dose of dexamethasone used in the present study was lower than AC, the toxicity of dexamethasone was significantly greater than AC in vitro and in vivo. It was observed in this study that the weight of dexamethasone-treated CIA mice was significantly reduced, while that of AC-treated group had no obvious change (Figure 2), suggesting the application of AC as a novel therapeutic agent for human RA or as an effective lead compound for the discovery of anti-RA drugs.

Previous reports have suggested that agents simultaneously inhibiting the NO and PGE2 production may show synergistic effects against chronic inflammation (Sakaguchi et al., 2006; $\mathrm{Li}$ et al., 2013). The results of our study revealed that AC at various concentrations downregulated the COX-2 and iNOS enzymes at the mRNA expression level and iNOS at the protein expression level in LPS-stimulated RAW 264.7 cells. Although the exact pathology of RA is unclear, proinflammatory cytokines and mediators are involved in the pathogenesis of arthritis 
A

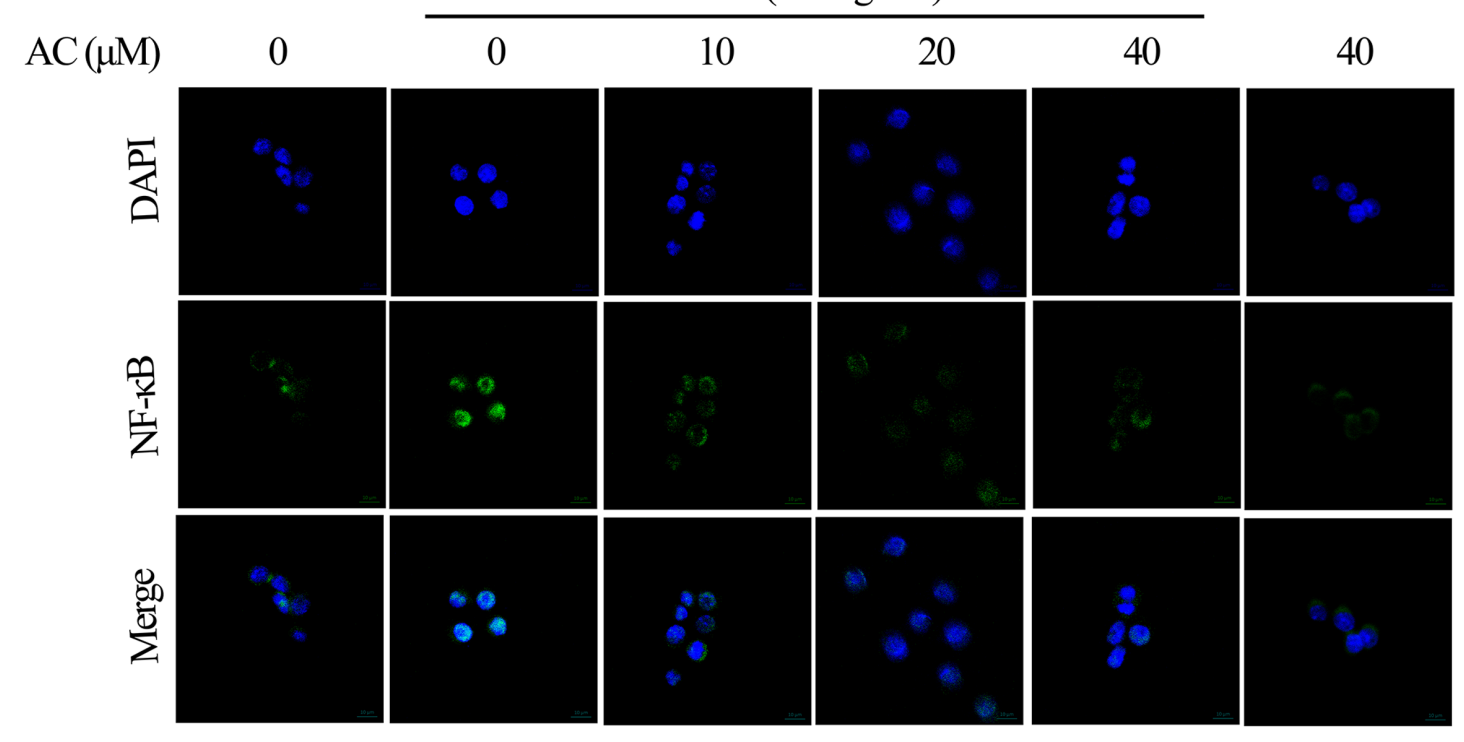

LPS (100 ng/mL)

B

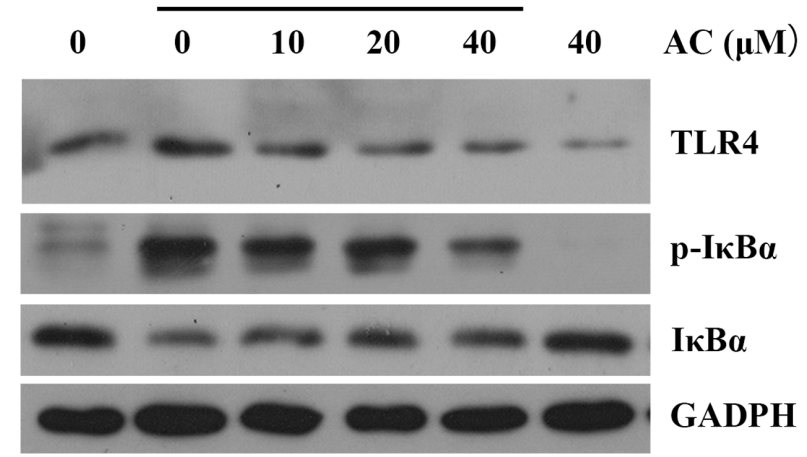

FIGURE 9 | (A) Effects of AC on the nuclear NF-кB translocation in LPS-induced RAW 264.7 cells. RAW 264.7 cells were pretreated with AC (10, 20 , and $40 \mu$ M) for $2 \mathrm{~h}$, followed by incubation with LPS (100 ng/mL) for $30 \mathrm{~min}$, and nuclear translocation of NF-kB was observed by confocal microscopy ( 63 ). (B) Effects of AC on the expression levels of TLR4, the cytoplasmic $\mathbf{l}_{\kappa} \mathrm{B} \alpha$ as well as the phosphorylation level of cytoplasmic $I_{\kappa} \mathrm{B} \alpha$.

(McInnes and Schett, 2007; Klareskog et al., 2009). Published data have revealed that TNF- $\alpha$ and IL-1 $\beta$ could promote the RA progress through mediators such as COX-2 and MMPs (Wu et al., 2016b). Among cytokines, TNF- $\alpha$ plays a vital role in RA, inducing inflammatory cytokine cascades in vivo and facilitating the osteoclast differentiation, formation, activation, and apoptosis, which ultimately leads to the erosion of the articular cartilage and bone (Yuan et al., 2012). A previous study has reported that human TNF-transgenic mice are an animal model of spontaneous development of arthritis to study therapeutics for RA. A TNF- $\alpha$-specific antibody and a soluble TNF receptor showed a prophylactic efficacy in the mouse model (Bevaart et al., 2010; Wang et al., 2016). In RA patients, the joint fluid and plasma contain high concentrations of IL6 , which is critical for the differentiation and activation of osteoclasts and bone resorption and enhances the vascular permeability of synovial tissue through stimulation of excess production of vascular endothelial growth factor (Yao et al., 2014). Furthermore, numerous studies have reported that IL6 blocks the regulatory $T$ (Treg) cell activity and inhibits Treg generation induced by transforming growth factor beta. Moreover, IL-6 promotes T helper 17 (Th17) cell differentiation as a regulator of the Treg/Th17 cell balance (Assier et al., 2010; Yoshida and Tanaka, 2014). Our results demonstrated that AC significantly suppressed the LPS-induced mRNA expression and secretion of TNF- $\alpha$, IL- $1 \beta$, and IL- 6 in vitro, and the TNF- $\alpha$ tissue production extremely decreased in AC-treated CIA mice (Figure 7). Hence, AC could exert its anti-arthritic effects, at least partially, through inhibition of excessive production of iNOS, COX-2, TNF- $\alpha$, IL-1 $\beta$, and IL-6.

Mitogen-activated protein kinase pathways are critical in regulating progressive joint destruction in RA. The MAPK family consists of three main subfamily members, ERK, p38, and JNK. JNK and p38 MAPKs play critical roles in regulating 
synovial invasion, inflammatory cytokine secretion by activated macrophages, and collagenase synthesis by RA FLSs, while ERK MAPK promotes the production of several cytokines and pannus formation (Ganesan et al., 2016; Ross et al., 2016; Yang et al., 2016). Thus, it has been suggested that inhibitors targeting the p38 and JNK MAPK pathways have anti-inflammatory activity (Kaminska, 2005). In the present study, we detected inhibitory effects of AC on the LPS-induced phosphorylation of MAPKs in RAW 264.7 cells. In particular, we found that AC inhibited the LPS-triggered phosphorylation of p38 and JNK but had little effect on that of ERK. These results suggest that the effects of $\mathrm{AC}$ on the production of inflammatory mediators and cytokines are likely mediated through blocking of the p38 and JNK signaling pathways in monocytic cells (Figure 8).

It is well established that $N F-\kappa B$ signaling plays a vital role in the progress and development of RA by regulating the transcription of pro-inflammatory mediators such as iNOS, COX-2, TNF- $\alpha$, IL-1 $\beta$, and IL- 6 in activated macrophages (Li et al., 2013; Yang et al., 2016). The activation of NF-кB and translocation of the p65 subunit to the nucleus is preceded by the phosphorylation, ubiquitination, and degradation of I $\mathrm{B} \alpha$ (Torices et al., 2015). In this study, we showed that AC significantly attenuated the LPS-induced IКB phosphorylation and degradation as well as the nuclear translocation of p65 in LPS-stimulated cultured RAW 264.7 cells, as demonstrated by the results of western blot and immunocytochemistry for NF- $\kappa$ B p65 (Figure 9). LPS from the cellular wall of Gram-negative bacteria plays a key role in producing an inflammatory response. Many studies have reported that LPS triggers the immune response via TLR4 and activates the NF- $\kappa \mathrm{B}$ and MAPKs signaling pathways to regulate the production of inflammatory cytokines, chemokines and tissue destructive enzymes (Park et al., 2013). To investigate the upstream signaling transduction mechanism, we determined the effect of AC on the expression level of TLR4 in LPSinduced RAW 264.7 cells. The results showed that AC decreased the expression level of TLR4 in a dose-dependent manner (Figure 9B), suggesting that AC might suppressed the activation of NF- $\kappa B$ and MAPK signaling pathways by the down-regulation of TLR4. In addition, it has been reported that triterpenoids exhibited potential anti-inflammatory activity by targeting PDE4

\section{REFERENCES}

Assier, E., Boissier, M.-C., and Dayer, J.-M. (2010). Interleukin-6: from identification of the cytokine to development of targeted treatments. Joint Bone Spine 77, 532-536. doi: 10.1016/j.jbspin.2010.07.007

Bevaart, L., Vervoordeldonk, M. J., and Tak, P. P. (2010). Evaluation of therapeutic targets in animal models of arthritis: how does it relate to rheumatoid arthritis? Arthritis Rheum. 62, 2192-2205. doi: 10.1002/art.27503

Brand, D. D., Latham, K. A., and Rosloniec, E. F. (2007). Collagen-induced arthritis. Nat. Protoc. 2, 1269-1275. doi: 10.1038/nprot.2007.173

Desai, R. J., Rao, J. K., Hansen, R. A., Fang, G., Maciejewski, M., and Farley, J. (2014). Tumor necrosis factor-alpha inhibitor treatment and the risk of incident cardiovascular events in patients with early rheumatoid arthritis: a nested case-control study. J. Rheumatol. 41, 2129-2136. doi: 10.3899/jrheum.131464

Fu, Q., Zan, K., Zhao, M., Zhou, S., Shi, S., Jiang, Y., et al. (2010). Triterpene saponins from Clematis chinensis and their potential
(Tan et al., 2017), Keap1-Nrf2 (Zhuang et al., 2014), COX-1 and/or COX-2 (Fu et al., 2010; Niu et al., 2014; Rauf et al., 2016). Whether AC could inhibit the function of the above proteins are worthy of further investigation.

In summary, our study provides evidence that AC causes a therapeutic effect on an LPS-enhanced CIA mouse model through inhibition of production of proinflammatory cytokines such as TNF- $\alpha$, IL- $1 \beta$, and IL- 6 as well as other mediators such as iNOS and COX-2. Furthermore, AC down-regulates TLR4, deregulates the activities of MAPK signaling pathways and suppresses the NF- $\kappa \mathrm{B}$ signaling pathway. The findings from the present in vitro and in vivo study suggest that $\mathrm{AC}$ has the potential to be developed as a novel therapeutic agent for human RA.

\section{AUTHOR CONTRIBUTIONS}

Participated in research design: ZL, M-ML, and W-CY. Conducted experiments: QL, X-HX, L-BH, H-YJ, ZL, and M-ML. Contributed new reagents or analytic tools: QL, X-HX, ZL, and M-ML. Performed data analysis: QL, X-HX, L-BH, ZL, M-ML, $\mathrm{H}-\mathrm{YJ}$, and YW. Wrote or contributed to the writing of the manuscript: QL, X-HX, ZL, M-ML, and W-CY.

\section{FUNDING}

This work was supported by the National Natural Science Foundation of China (81302654 and 81673670), the Science Technology Project for Guangdong Province (2013B090600144), the Science and Technology Program of Guangzhou (201610010108), the Key Laboratory for the Chemistry and Molecular Engineering of Medicinal Resources (Guangxi Normal University), Ministry of Education of China (CMEMR2015-B08), and Jinan Double Hundred Talents Plan.

\section{SUPPLEMENTARY MATERIAL}

The Supplementary Material for this article can be found online at: http://journal.frontiersin.org/article/10.3389/fphar. 2017.00299/full\#supplementary-material

anti-inflammatory activity. J. Nat. Prod. 73, 1234-1239. doi: 10.1021/np10 0057y

Fu, Y., Liu, B., Zhang, N., Liu, Z., Liang, D., Li, F., et al. (2013). Magnolol inhibits lipopolysaccharide-induced inflammatory response by interfering with TLR4 mediated NF-kappaB and MAPKs signaling pathways. J. Ethnopharmacol. 145, 193-199. doi: 10.1016/j.jep.2012. 10.051

Ganesan, R., Doss, H. M., and Rasool, M. (2016). Majoon ushba, a polyherbal compound, suppresses pro-inflammatory mediators and RANKL expression via modulating NFKB and MAPKs signaling pathways in fibroblastlike synoviocytes from adjuvant-induced arthritic rats. Immunol. Res. 64, 1071-1086. doi: 10.1007/s12026-016-8794-x

Garcia-Carbonell, R., Divakaruni, A. S., Lodi, A., Vicente-Suarez, I., Saha, A., Cheroutre, H., et al. (2016). Critical role of glucose metabolism in rheumatoid arthritis fibroblast-like synoviocytes. Arthritis Rheumatol. 68, 1614-1626. doi: 10.1002/art.39608 
Han, L.-T., Fang, Y., Li, M.-M., Yang, H.-B., and Huang, F. (2013). The antitumor effects of triterpenoid saponins from the anemone flaccida and the underlying mechanism. Evid. Based Complement Alternat. Med. 2013, 1-8. doi: 10.1155/ 2013/517931

Han, L. T., and Huang, F. (2009). [Studies on triterpenoid saponins in the rhizome of Anemone flaccida]. Zhong Yao Cai 32, 1059-1062.

Huang, Q. Q., and Pope, R. M. (2009). The role of toll-like receptors in rheumatoid arthritis. Curr. Rheumatol. Rep. 11, 357-364. doi: 10.1007/s11926-009-0051-z

Huang, X.-J., Tang, J.-Q., Li, M.-M., Liu, Q., Li, Y.-L., Fan, C.-L., et al. (2014). Triterpenoid saponins from the rhizomes of Anemone flaccida and their inhibitory activities on LPS-induced NO production in macrophage RAW264. 7 cells. J. Asian. Nat. Prod. Res. 16, 910-921. doi: 10.1080/10286020.2014. 954554

Kaminska, B. (2005). MAPK signalling pathways as molecular targets for antiinflammatory therapy-from molecular mechanisms to therapeutic benefits. Biochim. Biophys. Acta 1754, 253-262. doi: 10.1016/j.bbapap.2005.08.017

Klareskog, L., Catrina, A. I., and Paget, S. (2009). Rheumatoid arthritis. Lancet 373, 659-672. doi: 10.1016/s0140-6736(09)60008-8

Kumar, R., Gupta, Y. K., Singh, S., and Patil, A. (2016). Glorisa superba hydroalcoholic extract from tubers attenuates experimental arthritis by downregulating inflammatory mediators, and phosphorylation of ERK/JNK/p38. Immunol. Invest. 45, 603-618. doi: 10.1080/08820139.2016.1195406

Kunanusornchai, W., Witoonpanich, B., Tawonsawatruk, T., Pichyangkura, R., Chatsudthipong, V., and Muanprasat, C. (2016). Chitosan oligosaccharide suppresses synovial inflammation via AMPK activation: An in vitro and in vivo study. Pharmacol. Res. 113(Pt A), 458-467. doi: 10.1016/j.phrs.2016.09.016

Li, X., Peng, F., Xie, C., Wu, W., Han, X., and Chen, L. (2013). (E)-3-(3,4-Dimethoxyphenyl)-1-(5-hydroxy-2,2-dimethyl-2H-chromen-6yl)prop-2-en-1-one ameliorates the collagen-arthritis via blocking ERK/JNK and NF-кB signaling pathway. Int. Immunopharmacol. 17, 1125-1133. doi: 10.1016/j.intimp.2013.10.001

Liu, Q., Zhu, X.-Z., Feng, R.-B., Liu, Z., Wang, G.-Y., Guan, X.-F., et al. (2015). Crude triterpenoid saponins from Anemone flaccida ( $\mathrm{Di} \mathrm{Wu}$ ) exert antiarthritic effects on type II collagen-induced arthritis in rats. Chin. Med. 10, 20. doi: 10.1186/s13020-015-0052-y

McInnes, I. B., and Schett, G. (2007). Cytokines in the pathogenesis of rheumatoid arthritis. Nat. Rev. Immunol. 7, 429-442. doi: 10.1038/nri2094

Mu, N., Gu, J., Huang, T., Zhang, C., Shu, Z., Li, M., et al. (2016). A novel NF- $\kappa \mathrm{B} / \mathrm{YY} 1 /$ microRNA-10a regulatory circuit in fibroblast-like synoviocytes regulates inflammation in rheumatoid arthritis. Sci. Rep. 6:20059. doi: 10.1038/ srep20059

Niu, X., Mu, Q., Li, W., Yao, H., Li, H., and Huang, H. (2014). Esculentic acid, a novel and selective COX-2 inhibitor with anti-inflammatory effect in vivo and in vitro. Eur. J. Pharmacol. 740, 532-538. doi: 10.1016/j.ejphar.2014.06.034

Park, S. Y., Lee, S. W., Baek, S. H., Lee, C. W., Lee, W. S., Rhim, B. Y., et al. (2013). Suppression of PU.1-linked TLR4 expression by cilostazol with decrease of cytokine production in macrophages from patients with rheumatoid arthritis. Br. J. Pharmacol. 168, 1401-1411. doi: 10.1111/bph.12021

Rauf, A., Maione, F., Uddin, G., Raza, M., Siddiqui, B. S., Muhammad, N., et al. (2016). Biological evaluation and docking analysis of daturaolone as potential cyclooxygenase inhibitor. Evid. Based Complement Alternat. Med. 2016:4098686. doi: 10.1155/2016/4098686

Ross, E. A., Naylor, A. J., O’Neil, J. D., Crowley, T., Ridley, M. L., Crowe, J., et al. (2016). Treatment of inflammatory arthritis via targeting of tristetraprolin, a master regulator of pro-inflammatory gene expression. Ann. Rheum. Dis. 76, 612-619. doi: 10.1136/annrheumdis-2016-209424

Sakaguchi, Y., Shirahase, H., Kunishiro, K., Ichikawa, A., Kanda, M., and Uehara, Y. (2006). Effect of combination of nitric oxide synthase and cyclooxygenase inhibitors on carrageenan-induced pleurisy in rats. Life Sci. 79, 442-447. doi: 10.1016/j.lfs.2006.01.022

Tan, B. X., Yang, L., Huang, Y. Y., Chen, Y. Y., Peng, G. T., Yu, S., et al. (2017). Bioactive triterpenoids from the leaves of Eriobotrya japonica as the natural PDE4 inhibitors. Nat. Prod. Res. doi: 10.1080/14786419.2017.1300796 [Epub ahead of print] doi: 10.1080/14786419.2017.1300796

Tang, M. W., Reedquist, K. A., Garcia, S., Fernandez, B. M., Codullo, V., VieiraSousa, E., et al. (2016). The prolactin receptor is expressed in rheumatoid arthritis and psoriatic arthritis synovial tissue and contributes to macrophage activation. Rheumatology 55, 2248-2259. doi: 10.1093/rheumatology/kew316
Torices, S., Alvarez-Rodriguez, L., Grande, L., Varela, I., Munoz, P., Pascual, D., et al. (2015). A truncated variant of ASCC1, a novel inhibitor of NF- B, is associated with disease severity in patients with rheumatoid arthritis. J. Immunol. 195, 5415-5420. doi: 10.4049/jimmunol.1501532

Udalova, I. A., Mantovani, A., and Feldmann, M. (2016). Macrophage heterogeneity in the context of rheumatoid arthritis. Nat. Rev. Rheumatol. 12, 472-485. doi: 10.1038/nrrheum.2016.91

Vincent, T. L., Williams, R. O., Maciewicz, R., Silman, A., and Garside, P. (2012). Mapping pathogenesis of arthritis through small animal models. Rheumatology 51, 1931-1941. doi: 10.1093/rheumatology/kes035

Wang, W., Li, Z., Meng, Q., Zhang, P., Yan, P., Zhang, Z., et al. (2016). Chronic calcium channel inhibitor verapamil antagonizes TNF- $\alpha$-mediated inflammatory reaction and protects against inflammatory arthritis in mice. Inflammation 39, 1624-1634. doi: 10.1007/s10753-016-0396-1

Wen, T., Li, Y., Wu, M., Sun, X., Bao, X., Lin, Y., et al. (2012). Therapeutic effects of a novel tylophorine analog, NK-007, on collagen-induced arthritis through suppressing tumor necrosis factor $\alpha$ production and Th17 cell differentiation. Arthritis Rheum. 64, 2896-2906. doi: 10.1002/art.34528

Wu, H., Zhao, G., Jiang, K., Chen, X., Zhu, Z., Qiu, C., et al. (2016a). Plantamajoside ameliorates lipopolysaccharide-induced acute lung injury via suppressing NF-kappaB and MAPK activation. Int. Immunopharmacol. 35, 315-322. doi: 10.1016/j.intimp.2016.04.013

Wu, Q., Wang, Y., Wang, Q., Yu, D., Wang, Y., Song, L., et al. (2016b). The bispecific antibody aimed at the vicious circle of IL-1 $\beta$ and IL-17A, is beneficial for the collagen-induced rheumatoid arthritis of mice through NF- $\kappa$ B signaling pathway. Immunol. Lett. 179, 68-79. doi: 10.1016/j.imlet.2016.09.001

Yang, Y., Ye, Y., Qiu, Q., Xiao, Y., Huang, M., Shi, M., et al. (2016). Triptolide inhibits the migration and invasion of rheumatoid fibroblast-like synoviocytes by blocking the activation of the JNK MAPK pathway. Int. Immunopharmacol. 41, 8-16. doi: 10.1016/j.intimp.2016.10.005

Yao, X., Huang, J., Zhong, H., Shen, N., Faggioni, R., Fung, M., et al. (2014). Targeting interleukin- 6 in inflammatory autoimmune diseases and cancers. Pharmacol. Ther. 141, 125-139. doi: 10.1016/j.pharmthera.2013.09.004

Yeo, L., Adlard, N., Biehl, M., Juarez, M., Smallie, T., Snow, M., et al. (2016). Expression of chemokines CXCL4 and CXCL7 by synovial macrophages defines an early stage of rheumatoid arthritis. Ann. Rheum. Dis. 75, 763-771. doi: 10.1136/annrheumdis-2014-206921

Yoshida, Y., and Tanaka, T. (2014). Interleukin 6 and Rheumatoid Arthritis. Biomed. Res. Int. 2014, 1-12. doi: 10.1155/2014/698313

You, X., Pan, M., Gao, W., Shiah, H. S., Tao, J., Zhang, D., et al. (2006). Effects of a novel tylophorine analog on collagen-induced arthritis through inhibition of the innate immune response. Arthritis Rheum. 54, 877-886. doi: 10.1002/art. 21640

Yuan, H., Qian, H., Liu, S., Zhang, X., Li, S., Wang, W., et al. (2012). Therapeutic role of a vaccine targeting RANKL and TNF- $\alpha$ on collagen-induced arthritis. Biomaterials 33, 8177-8185. doi: 10.1016/j.biomaterials.2012.07.047

Zhang, L. T., Zhang, Y. W., Takaishi, Y., and Duan, H. Q. (2008). Antitumor triterpene saponins from Anemone flaccida. Chin. Chem. Lett. 19, 190-192. doi: 10.1016/j.cclet.2007.11.029

Zhu, L., Chen, T., Chang, X., Zhou, R., Luo, F., Liu, J., et al. (2016) Salidroside ameliorates arthritis-induced brain cognition deficits by regulating Rho/ROCK/NF-кB pathway. Neuropharmacology 103, 134-142. doi: 10.1016/j. neuropharm.2015.12.007

Zhuang, C., Miao, Z., Sheng, C., and Zhang, W. (2014). Updated research and applications of small molecule inhibitors of Keap1-Nrf2 protein-protein interaction: a review. Curr. Med. Chem. 21, 1861-1870. doi: 10.2174/ 0929867321666140217104648

Conflict of Interest Statement: The authors declare that the research was conducted in the absence of any commercial or financial relationships that could be construed as a potential conflict of interest.

Copyright (c) 2017 Liu, Xiao, Hu, Jie, Wang, Ye, Li and Liu. This is an open-access article distributed under the terms of the Creative Commons Attribution License (CC BY). The use, distribution or reproduction in other forums is permitted, provided the original author(s) or licensor are credited and that the original publication in this journal is cited, in accordance with accepted academic practice. No use, distribution or reproduction is permitted which does not comply with these terms. 